\title{
Length of hospital stay after uncomplicated esophagectomy. Hospital variation shows room for nationwide improvement
}

\author{
Daan M. Voeten ${ }^{1,2,5}$ - Leonie R. van der Werf ${ }^{1}$. Johanna W. van Sandick ${ }^{3} \cdot$ Richard van Hillegersberg $^{4}$. \\ Mark I. van Berge Henegouwen ${ }^{1,6}$. on behalf of the Dutch Upper Gastrointestinal Cancer Audit Group
}

Received: 27 May 2020 / Accepted: 16 October 2020 / Published online: 26 October 2020

(c) The Author(s) 2020

\begin{abstract}
Background Within the scope of value-based health care, this study aimed to analyze Dutch hospital performance in terms of length of hospital stay after esophageal cancer surgery and its association with 30-day readmission rates. Since both parameters are influenced by the occurrence of complications, this study only included patients with an uneventful recovery after esophagectomy.

Methods All patients registered in the Dutch Upper Gastrointestinal Cancer Audit (DUCA) who underwent a potentially curative esophagectomy between 2015 and 2018 were considered for inclusion. Patients were excluded in case of an intraoperative/post-operative complication, readmission to the intensive care unit, or any re-intervention. Length of hospital stay was dichotomized around the national median into 'short admissions' and 'long admissions'. Hospital variation was evaluated using a case-mix-corrected funnel plot based on multivariable logistic regression analyses. Association of length of hospital stay with 30 -day readmission rates was investigated using the $\chi^{2 \text {-statistic. }}$

Results A total of 1007 patients was included. National median length of hospital stay was 9 days, ranging from 6.5 to 12.5 days among 17 hospitals. The percentage of 'short admissions' per hospital ranged from 7.7 to $93.5 \%$. After correction for case-mix variables, 3 hospitals had significantly higher 'short admission' rates and 4 hospitals had significantly lower 'short admission' rates. Overall, 6.2\% [hospital variation (0.0-13.2\%)] of patients were readmitted. Hospital 30-day readmission rates were not significantly different between patients with a short length of hospital stay and those with a long length of hospital stay $(5.5 \%$ versus $7.6 \% ; p=0.19)$.

Conclusions Based on these nationwide audit data, median length of hospital stay after an uncomplicated esophagectomy was 9 days ranging from 6.5 to 12.5 days among Dutch hospitals. There was no association between length of hospital stay and readmission rates. Nationwide improvement might lead to a substantial reduction of hospital costs.
\end{abstract}

Keywords Esophageal carcinoma $\cdot$ Length of hospital stay $\cdot$ Readmission $\cdot$ Hospital volume $\cdot$ Hospital variation

Electronic supplementary material The online version of this article (https://doi.org/10.1007/s00464-020-08103-4) contains supplementary material, which is available to authorized users.

Daan M. Voeten

d.voeten@amsterdamumc.nl

Mark I. van Berge Henegouwen

m.i.vanbergehenegouwen@amsterdamumc.nl

1 Department of Surgery, Amsterdam UMC, Location AMC, Cancer Centre Amsterdam, University of Amsterdam, Amsterdam, The Netherlands

2 Scientific Bureau, Dutch Institute for Clinical Auditing, Leiden, The Netherlands

3 Department of Surgical Oncology, Antoni Van Leeuwenhoek Hospital, Amsterdam, The Netherlands
4 Department of Surgery, University Medical Centre Utrecht, Utrecht, The Netherlands

5 Department of Surgery, Amsterdam UMC, Location AMC, Room G4-180, Meibergdreef 9, 1105 AZ Amsterdam, The Netherlands

6 Department of Surgery, Amsterdam UMC, Location AMC, Room G6-25, Meibergdreef 9, 1105 AZ Amsterdam, The Netherlands 
Potentially curative treatment for locally advanced esophageal carcinoma consists of (neo)adjuvant chemo(radio) therapy followed by surgical resection. Esophagectomy is associated with significant post-operative morbidity. Approximately $65 \%$ of Dutch patients undergoing esophageal cancer surgery have a post-operative complication and 29\% experience severe complications [1]. Post-operative complications are related to an increased length of hospital stay $[2,3]$. In literature, median length of hospital stay after esophageal resection ranges from 8 to 14 days [3-6]. Prolonged length of hospital stay is a negative outcome of esophageal cancer surgery, not only for the patient but also for hospital finances [7-10]. In addition, complications have been related to higher readmission rates [11-15]. Hospital readmission also imposes a burden on patients and leads to an increase in hospital costs [7-9]. The relation between length of hospital stay and readmission has not been investigated in large cohorts of esophagectomy patients.

The 'Dutch Upper GI Cancer audit' (DUCA) aims to improve quality of care for surgically treated patients with esophageal or gastric cancer by benchmarking hospital results, and thus identifying variation in treatment, outcomes and clinical care pathways [16]. Reduction of hospital variation may enhance outcomes of care at a population level [17]. Next to quality of care, there is an increasing interest in value-based health care in oncology worldwide [18]. Comparing length of hospital stay and readmission rates after esophagectomy provides important insight into the efficiency of different post-operative care pathways and clinical practices in the Netherlands. Within that scope, this study aimed to analyze Dutch hospital performance in terms of length of hospital stay after esophageal cancer surgery and its association with 30-day hospital readmission rates. This study hypothesizes that hospital variation exists without higher readmission rates in hospitals with a short hospital stay. Since both parameters are influenced by the occurrence of complications, this study only included patients with an uneventful recovery after esophagectomy.

\section{Materials and methods}

\section{Study design}

For this population-based cohort study, data were retrieved from the DUCA dataset. This mandatory audit registers all patients with esophageal or gastric cancer undergoing surgery with the intent of resection since 2011. The DUCA dataset was verified; data completeness was estimated at 99.2\% and outcome measure accuracy ranged from 95.3 to 100\%.[19] As patients and hospitals are registered anonymously, ethical approval or informed consent was not needed according to Dutch Law. The current study protocol was approved by the DUCA scientific committee.

\section{Patient selection}

All esophageal carcinoma patients undergoing potentially curative surgery between 2015 and 2018 were considered for inclusion. Patients were excluded in case of an intraoperative and/or post-operative complication, readmission to the intensive care unit, or any re-intervention. In order to give an overview of the current situation in the Netherlands, patients undergoing surgery in hospitals where esophageal cancer surgery was stopped before 2018 were excluded, to prevent redundant exclusion causing selection bias the 2015-2018 timeframe was chosen. In addition, patients were excluded if length of hospital stay was unknown/invalid.

\section{Outcomes}

Length of hospital stay was calculated by subtracting the day of surgery from the day of discharge. In case date of discharge was before, or more than 200 days after the date of surgery, the entry was considered invalid. In the DUCA, short-term surgical outcomes are registered. Readmission is registered until 30 days after discharge from the hospital.

\section{Statistical analyses}

Median length of hospital was reported at national and hospital level. Given its skewed distribution, length of hospital stay was dichotomized around the national median into 'short admissions' and 'long admissions'. The exact median was added to the short admission group. Baseline characteristics between both groups were compared using the $\chi^{2}$ or fisher's exact test. Hospital variation was evaluated using a case-mix corrected funnel plot [20,21]. The expected number of short admissions for each hospital based on their casemix was estimated using multivariable logistic regression analyses. The patient and tumor characteristics presented in Online Supplements Table 1 were used in the case-mix model. The observed number of short admissions divided by the estimated/expected (O/E ratio) was presented on the $y$-axis of the funnel plot, the $x$-axis showed the expected number. An O/E ratio larger than 1.0 indicated that more short admissions occurred than would be expected based on the hospital's case-mix, whereas a ratio smaller than 1.0 indicated that less events occurred. Patients of outperforming and underperforming hospitals were pooled and 30-day readmission rates were compared using the $\chi 2$-statistic.

Univariable and multivariable logistic regression assessed possible factors associated with a long admission. Next to the 
baseline characteristics in Online Supplements Table 1, the following factors were investigated: hospital volume (the annual total esophagectomy hospital volume was assigned to each patient and thereafter dichotomized into $<40$ or $>40$ ), neoadjuvant therapy (chemoradiotherapy, none, chemotherapy), operative procedure (minimally invasive transthoracic, minimally invasive transhiatal, minimally invasive other, hybrid surgery, open transthoracic, open transhiatal and other open surgery), and anastomotic site (cervical, intrathoracic). Factors with a $p$-value $<0.1$ in univariable analyses were added to multivariable analysis. To assess the association between length of hospital stay and 30-day readmission, the analyses above were repeated with readmission as dependent variable. Next to the variables described above, discharge during the weekend and length of hospital stay were added to this model.

\section{Sensitivity analyses}

Based on previously published literature this study assumed complications impact length of hospital stay. This sensitivity analyses investigates this assumption in the DUCA dataset in order to prevent redundant exclusion of patients if the assumption does not apply. For these analyses, patients both with and without complications were included. Median length of hospital stay was reported at national level for the total cohort, patients with complications and patients with severe complications (grade Clavien Dindo grade 3 or higher) [22].

All p-values were two-sided, a $p<0.05$ was considered statistically significant. Multicollinearity was assessed in all multivariable analyses using the variance inflation factor (VIF), a VIF $\geq 2.5$ was considered indicative of multicollinearity. Missing values were analyzed in separate groups if exceeding 5\%. Data were analyzed using R-studio version 1.2.5019, The R Foundation for Statistical Computing [23].

\section{Results}

A total of 1007 patients from 17 hospitals was included for analyses (Fig. 1). National median length of hospital stay after an uncomplicated esophagectomy was 9 days (IQR 7.0-11.0). Median length of hospital stay ranged from 6.5 (IQR 6.0-7.0) to 12.5 days (IQR 11.0-13.0) among the 17 hospitals (Fig. 2A). After dichotomization ( $\leq 9$ days and $>9$ days), 646 patients (64.2\%) had a short admission and 361 patients $(35.8 \%)$ had a long admission. Median length of stay was 8 days in the short admission group and 11 in the long admission group. The percentage of short admissions per hospital ranged from 7.7 to 93.5\% (Fig. 2B). After correction for case-mix variables, the funnel plot showed 3 hospitals had significantly higher short admission rates and 4 hospitals had significantly lower short admissions rates than expected (Fig. 3).

\section{Clinical factors associated with prolonged length of hospital stay}

Baseline patient, tumor, and treatment characteristics of patients with short admissions and long admissions are shown in Table 1.

In multivariable logistic regression analyses, no neoadjuvant therapy, a hospital volume of under 40 esophagectomies per year and higher than average hospital complication rates were statistically associated with a long admission (Table 2). Compared to minimally invasive transthoracic surgery both open and minimally invasive transhiatal surgery and other minimally invasive surgery were associated with short admissions. Open transthoracic and hybrid surgery were associated with long admissions.

\section{Readmission}

Of the 1007 included patients, 12 had missing data on readmission status. Overall, 62 of 995 patients $(6.2 \%)$ were readmitted. The 30 -day readmission rate ranged from 0.0 to $13.2 \%$ among hospitals. 30 -day mortality occurred in one patient without readmission. There was no 30-day mortality among the 62 readmitted patients. Charlson Comorbidity Index, neoadjuvant therapy and surgical procedure were associated with readmission (Table 3). In addition, the readmission rate after discharge during the weekend was $10.2 \%$ (13 of 128) and 5.7\% (49 of 867) after weekday discharge $(p=0.049)$. Hospital 30-day readmission rates were not significantly different between patients with a short admission and those with a long admission (5.5\% vs $7.6 \%$, respectively, $p=0.19$ ). Given the small number of degrees of freedom, and small group sizes multivariable logistic regression analyses was not possible.

A total of 179 patients underwent surgery in the 3 outperforming hospitals (with more short admissions), of whom 10 were readmitted (5.6\%). In the 4 underperforming hospitals (with fewer short admissions) $6.3 \%$ of 143 patients was readmitted, which was similar to the outperforming hospitals $(p=0.79)$.

\section{Sensitivity analyses}

In total, 3086 patients underwent potentially curative surgery for esophageal carcinoma. Median length of hospital stay in this cohort was 11 days (IQR 8.0-18.0). Median length of hospital stay in patients with post-operative complications was 15 days (IQR 10.0-25.0). After a severe complication (Clavien Dindo grade 3 or higher), median length of hospital stay was 23 days (IQR 15.0-39.0). 


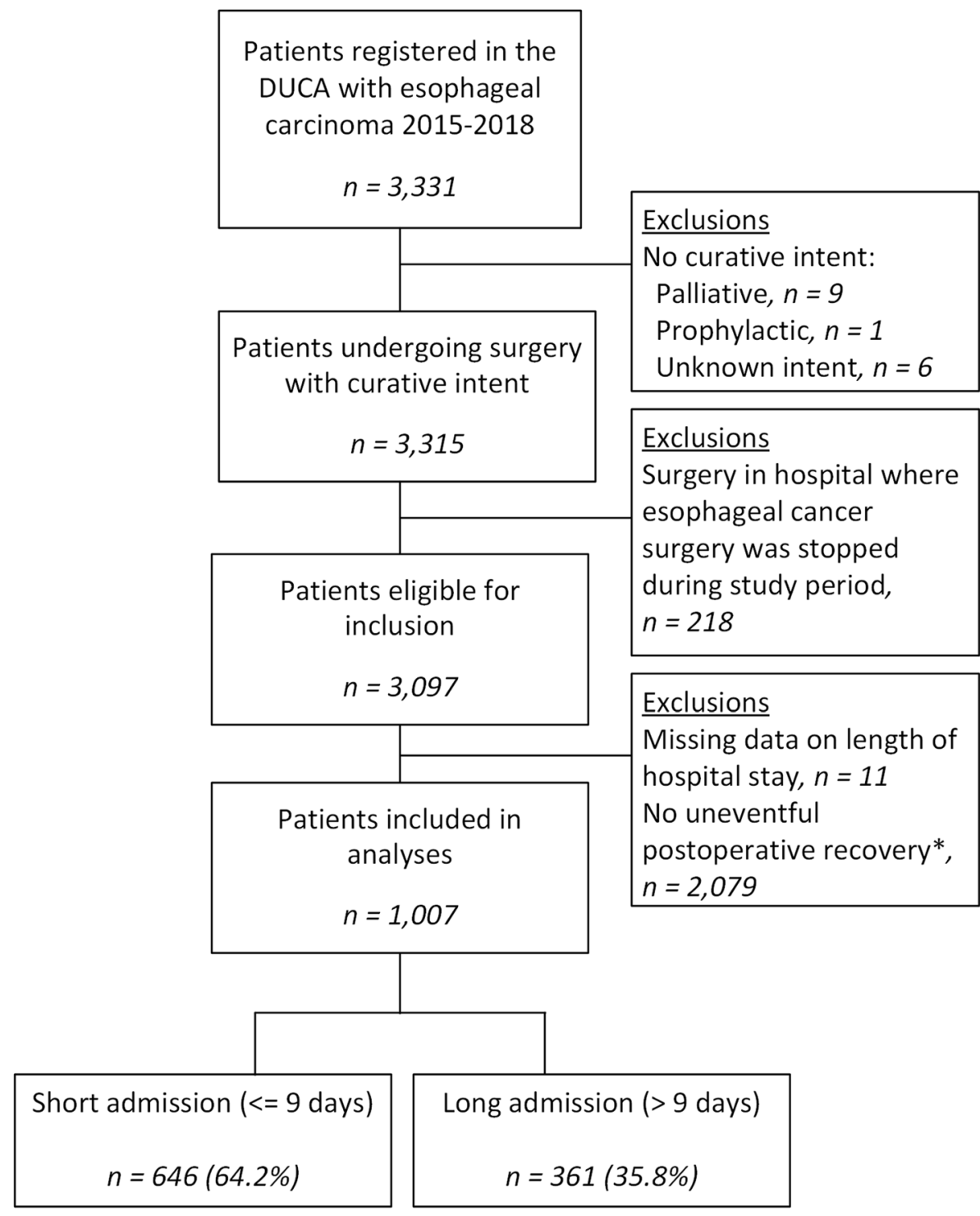

* Uneventful recovery: no intraoperative and/or postoperative complication, readmission to the intensive care unit, or any re-intervention.

Fig. 1 Flowchart of the study

Online Supplements Table 2 shows associated factors with a long admission in this cohort.

\section{Discussion}

This study showed hospital variation in length of hospital stay after uncomplicated esophageal resection for cancer. Median length of hospital stay ranged from 6.5 to 12.5 days among Dutch hospitals. In the current cohort, readmission rates after a short hospital stay and after a long hospital stay were comparable. However, readmission rates were higher in patients who were discharged in the weekend.

A retrospective cohort study using the NSQIP dataset, including over 3500 patients, reported a median hospital stay of 11 days after esophagectomy [3]. This is comparable to the median length of hospital stay in the sensitivity analyses of the current study. They did not report length of hospital stay for uncomplicated patients, but they did find complications to negatively affect length of hospital stay. This is similar to the results of our sensitivity analyses which showed median length of hospital stay was 15 days for complicated 
A Median length of hospital stay per hospital

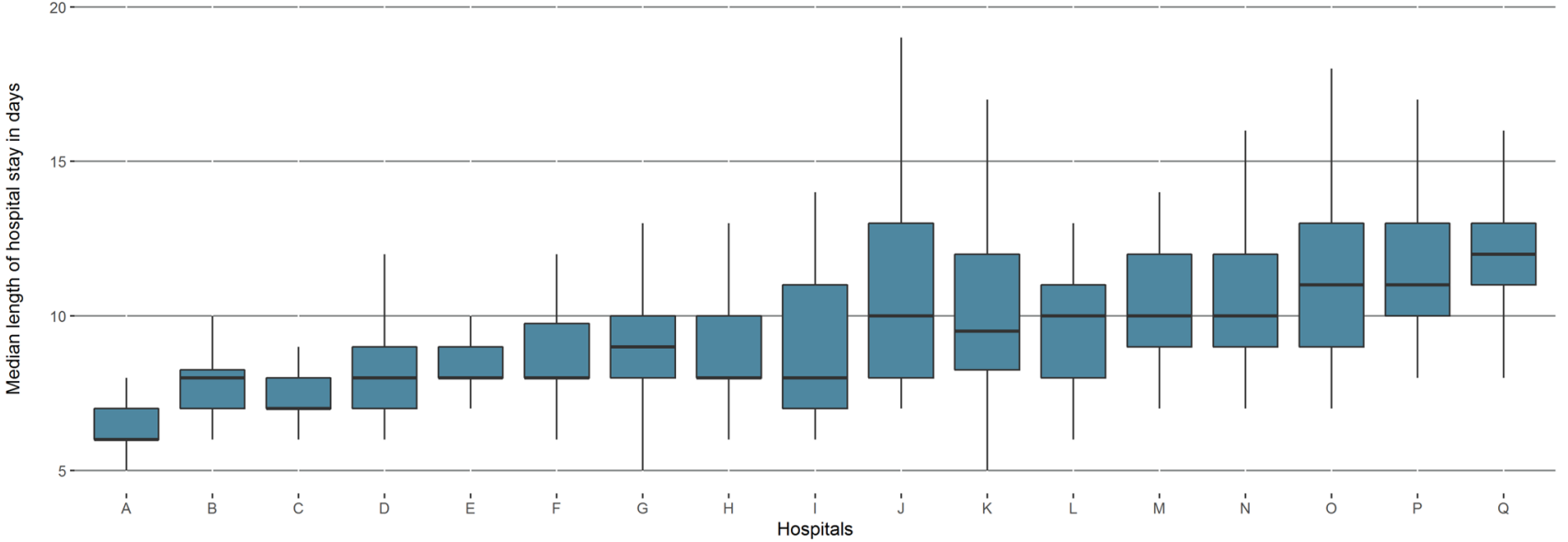

B Percentage short hospital stay ( $<=9$ days) per hospital

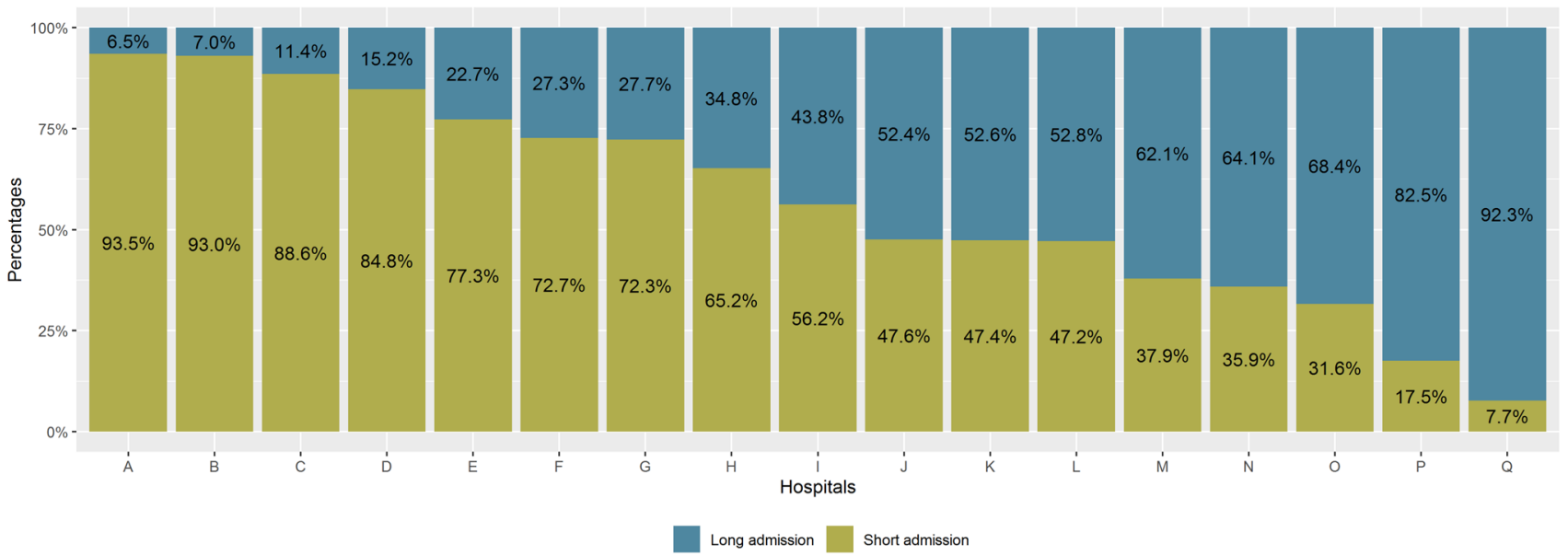

Fig. 2 A Median length of hospital stay after uncomplicated esophagectomy per hospital. B Percentage of short ( $\leq 9$ days) and long ( $>9$ days) hospital admissions after uncomplicated esophagectomy per hospital

patients and 23 days for severely complicated patients. Several other retrospective studies also concluded that complications lead to longer hospital admissions $[4,24,25]$. To our knowledge, no literature is available on hospital variation in length of stay after uncomplicated esophagectomy. In the current study, median length of hospital stay had a 6-day difference between hospitals. Since only patients without complications were included, this difference is likely being caused by differences in clinical care pathways or discharge logistics. The hospitals with longer hospital stay might have difficulties in finding appropriate in-home care, or available nursing home beds. The timing of critical components of post-esophagectomy care (e.g., extubation, early mobilization, intensive care unit discharge, etc.) influences length of hospital stay [26]. In addition, several studies, including a meta-analysis of 18 studies, showed that the availability of a fast track or enhanced recovery after surgery (ERAS) protocol is associated with a shorter length of hospital stay [27-30]. The DUCA does not register ERAS protocol availability, therefore this statement could not be verified in the current study. Future DUCA research will focus on identifying the true reasons for hospital variation in length of hospital stay, afterwards focused improvement trajectories will be initiated.

Dutch upper gastrointestinal surgeons have yearly meetings in which different practices, logistics and clinical care pathways are discussed. These meetings aim to reduce hospital variation in upper gastrointestinal practices and outcomes. Discussing discharge logistics and clinical care pathways, or nationwide implementation of fast track recovery programs, may reduce hospital variation in length of hospital stay and eventually provoke a nationwide reduction in length of hospital stay and therefore hospital costs $[8,25]$. Similar expert sessions were organized in the United Kingdom on different anastomotic techniques with positive results [31].

The Dutch guideline recommends neoadjuvant chemoradiotherapy for locally advanced esophageal cancer; at over $85 \%$ the compliance rate is high $[32,33]$. Patients not 


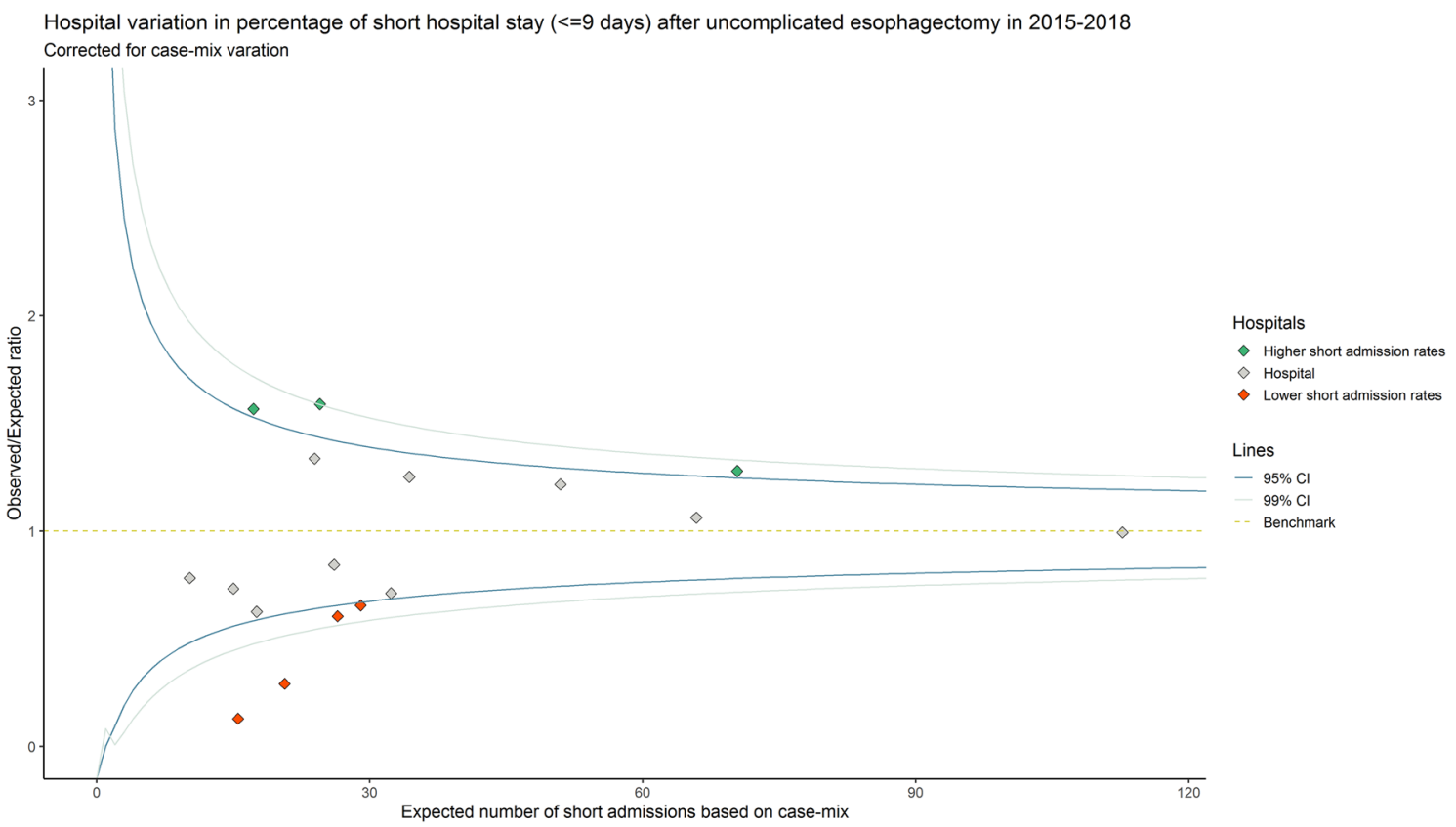

Fig. 3 Case-mix-corrected funnel plot showing hospital variation in length of hospital stay after uncomplicated esophagectomy

receiving neoadjuvant therapy are probably not fit enough to receive intensive systemic therapy, which explains the longer hospital stay in these patients. In the current study, transthoracic surgery was associated with prolonged length of hospital stay which is in line with the results of a large meta-analyses comparing transhiatal and transthoracic surgery [34]. The opening of the thorax and more extensive lymph node dissection of transthoracic surgery might require longer in-hospital recovery independent of complications [35]. This study also showed shorter length of hospital stay in high-volume hospitals. This result corresponds with that of a systematic review and meta-analysis published in 2018 [36]. This study investigated the relationship between hospital volume and length of hospital stay after esophageal carcinoma surgery. A total of 75,383 patients were included and the authors concluded length of hospital stay was inversely related to hospital volume. In the current study, only uncomplicated patients were included, therefore the difference in hospital stay between low and high-volume hospitals was not caused by lower complication rates in the latter. High-volume hospitals might have invested more in efficient discharge logistics, clinical care pathways or ERAS protocols. More experienced nurses and residents may also play a role in faster discharge. This study also showed prolonged stay in hospitals with high complication rates, even for uncomplicated patients. This might be because of habit or fear of complications but might also reflect overlap with the volume-outcome relationship: shorter hospital stay and lower complication rates in high-volume hospitals [37].

Several studies investigated hospital readmission after esophagectomy, with readmission occurring in $11.2 \%$ to $18.6 \%[13,14,38-40]$. These rates are higher than the $6.2 \%$ found in the current study but many of these studies found post-operative complications to be the biggest risk factor for a readmission. None of these reported on the effect of weekend discharge on readmission rates. Several studies investigated the effect of weekend discharge on readmission after other types of surgery than esophagectomy. None found higher readmission rates after weekend discharge [41-45]. All of these studies included patients both with and without complications. Given the results of the current study, even though not corrected for confounders, clinicians should be prudent in discharging (uncomplicated) esophagectomy patients during the weekend. Possibly, less continuity, and a decreased accuracy of discharge instructions, medication prescription, or home care planning could be the cause of a higher readmission rate after a weekend discharge. 
Table 1 Baseline characteristics of patients with short ( $\leq 9$ days) and long ( $>9$ days) admission after uncomplicated esophagectomy in 2015-2018

\begin{tabular}{|c|c|c|c|c|}
\hline & $\begin{array}{l}\text { Short } \\
\text { admission } \\
(\leq 9 \text { days })\end{array}$ & $\begin{array}{l}\text { Long } \\
\text { admission } \\
\text { (>9 days) }\end{array}$ & Total & $\begin{array}{l}P \text {-value } \\
\left(\chi^{2} /\right. \\
\text { Fisher })\end{array}$ \\
\hline & $N(\%)$ & $N(\%)$ & $N(\%)$ & \\
\hline Total & $646(64.2 \%)$ & $361(35.8 \%)$ & 1007 & \\
\hline Sex & & & & 0.06 \\
\hline Male & $524(81.1 \%)$ & $276(76.5 \%)$ & $800(79.4 \%)$ & \\
\hline Female & $120(18.6 \%)$ & $85(23.5 \%)$ & $205(20.4 \%)$ & \\
\hline Missing & $2(0.3 \%)$ & $0(0 \%)$ & $2(0.2 \%)$ & \\
\hline Age in years & & & & 0.53 \\
\hline$<65$ & $291(45.0 \%)$ & $153(42.4 \%)$ & $444(44.1 \%)$ & \\
\hline $65-75$ & $304(47.1 \%)$ & $173(47.9 \%)$ & $477(47.4 \%)$ & \\
\hline$>75$ & $51(7.9 \%)$ & $35(9.7 \%)$ & $86(8.5 \%)$ & \\
\hline Preoperative weight loss ${ }^{\mathrm{a}}$ & & & & 0.65 \\
\hline None & $206(31.9 \%)$ & $128(35.5 \%)$ & $334(33.2 \% 0$ & \\
\hline $1-5$ & $191(29.6 \%)$ & $97(26.9 \%)$ & $288(28.6 \%)$ & \\
\hline $6-10$ & $149(23.1 \%)$ & $79(21.9 \%)$ & $228(22.6 \%)$ & \\
\hline$>10$ & $77(11.9 \%)$ & $44(12.2 \%)$ & $121(12.0 \%)$ & \\
\hline Missing & $23(3.6 \%)$ & $13(3.6 \%)$ & $36(3.6 \%)$ & \\
\hline Body mass index (BMI) & & & & 0.32 \\
\hline$<20$ & $37(5.7 \%)$ & $28(7.8 \%)$ & $65(6.5 \%)$ & \\
\hline $20-25$ & $328(50.8 \%)$ & $165(45.7 \%)$ & $493(49.0 \%)$ & \\
\hline $26-30$ & $208(32.2 \%)$ & $120(33.2 \%)$ & $328(32.6 \%)$ & \\
\hline$>30$ & $73(11.3 \%)$ & $48(13.3 \%)$ & $121(12.0 \%)$ & \\
\hline ASA score ${ }^{b}$ & & & & 0.73 \\
\hline I & $132(20.4 \%)$ & $67(18.6 \%)$ & $199(19.8 \%)$ & \\
\hline II & $401(62.1 \%)$ & $227(62.9 \%)$ & $628(62.4 \%)$ & \\
\hline $\mathrm{III}+$ & $112(17.3 \%)$ & $67(18.6 \%)$ & $179(17.8 \%)$ & \\
\hline Missing & $1(0.2 \%)$ & $0(0 \%)$ & $1(0.1 \%)$ & \\
\hline $\mathrm{CCI}^{\mathrm{c}}$ & & & & 0.18 \\
\hline 0 & $363(56.2 \%)$ & $182(50.4 \%)$ & $545(54.1 \%)$ & \\
\hline 1 & $141(21.8 \%)$ & $94(26.0 \%)$ & $235(23.3 \%)$ & \\
\hline $2+$ & $142(22.0 \%)$ & $85(23.5 \%)$ & $227(22.5 \%)$ & \\
\hline Previous esophageal or gastric surgery & & & & 0.06 \\
\hline No & $635(98.3 \%)$ & $348(96.4 \%)$ & $983(97.6 \%)$ & \\
\hline Yes & $9(1.4 \%)$ & $12(3.3 \%)$ & $21(2.1 \%)$ & \\
\hline Missing & $2(0.3 \%)$ & $1(0.3 \%)$ & $3(0.3 \%)$ & \\
\hline Tumor location & & & & $<0.01$ \\
\hline Intrathoracic esophagus & $481(74.5 \%)$ & $298(82.5 \%)$ & $779(77.4 \%)$ & \\
\hline Gastro-esophageal junction & $165(25.5 \%)$ & $63(17.5 \%)$ & $228(22.6 \%)$ & \\
\hline Histology & & & & 0.20 \\
\hline Adenocarcinoma & $526(81.4 \%)$ & $281(77.8 \%)$ & $807(80.1 \%)$ & \\
\hline Squamous cell carcinoma & $93(14.4 \%)$ & $68(18.8 \%)$ & $161(16.0 \%)$ & \\
\hline Other & $13(2.0 \%)$ & $6(1.7 \%)$ & $19(1.9 \%)$ & \\
\hline Unknown/missing & $14(2.2 \%)$ & $6(1.7 \%)$ & $20(2.0 \%)$ & \\
\hline Clinical tumor stage ${ }^{\mathrm{d}}$ & & & & 0.19 \\
\hline T0-2 & $146(22.6 \%)$ & $98(27.1 \%)$ & $244(24.2 \%)$ & \\
\hline $\mathrm{T} 3-4$ & $470(72.8 \%)$ & $257(71.2 \%)$ & $727(72.2 \%)$ & \\
\hline Unknown/missing & $30(4.6 \%)$ & $6(1.7 \%)$ & $36(3.6 \%)$ & \\
\hline Clinical node stage ${ }^{\mathrm{d}}$ & & & & 0.68 \\
\hline No & $255(39.5 \%)$ & $140(38.8 \%)$ & $395(39.2 \%)$ & \\
\hline $\mathrm{N}+$ & $368(57.0 \%)$ & $215(59.6 \%)$ & $583(57.9 \%)$ & \\
\hline
\end{tabular}


Table 1 (continued)

\begin{tabular}{|c|c|c|c|c|}
\hline & $\begin{array}{l}\text { Short } \\
\text { admission } \\
(\leq 9 \text { days })\end{array}$ & $\begin{array}{l}\text { Long } \\
\text { admission } \\
\text { (>9 days) }\end{array}$ & Total & $\begin{array}{l}P \text {-value } \\
\left(\chi^{2} /\right. \\
\text { Fisher })\end{array}$ \\
\hline & $N(\%)$ & $N(\%)$ & $N(\%)$ & \\
\hline Unknown/missing & $23(3.6 \%)$ & $6(1.7 \%)$ & $29(2.9 \%)$ & \\
\hline Neoadjuvant therapy & & & & $<0.01$ \\
\hline Chemoradiotherapy & $566(87.6 \%)$ & $302(83.7 \%)$ & $868(86.2 \%)$ & \\
\hline None & $23(3.6 \%)$ & $41(11.4 \%)$ & $64(6.4 \%)$ & \\
\hline Chemotherapy & $57(8.8 \%)$ & $18(5.0 \%)$ & $75(7.4 \%)$ & \\
\hline Salvage surgery & & & & 1.00 \\
\hline No & $618(95.7 \%)$ & $347(96.1 \%)$ & $965(95.8 \%)$ & \\
\hline Yes & $8(1.2 \%)$ & $5(1.4 \%)$ & $13(1.3 \%)$ & \\
\hline Missing & $20(3.1 \%)$ & $9(2.5 \%)$ & $29(2.9 \%)$ & \\
\hline Hospital volume (esophageal resections per year) & & & & $<0.01$ \\
\hline$<40$ & $142(22.0 \%)$ & $134(37.1 \%)$ & $276(27.4 \%)$ & \\
\hline$\geq 40$ & $504(78.0 \%)$ & $227(62.9 \%)$ & $731(72.6 \%)$ & \\
\hline Surgical procedure & & & & $<0.01$ \\
\hline $\mathrm{MI}^{\mathrm{e}}$ transthoracic & $446(69.0 \%)$ & $236(65.4 \%)$ & $682(67.7 \%)$ & \\
\hline MI transhiatal & $40(6.2 \%)$ & $19(5.3 \%)$ & $59(5.9 \%)$ & \\
\hline MI other & $23(3.6 \%)$ & $4(1.1 \%)$ & $27(2.7 \%)$ & \\
\hline Hybrid & $24(3.7 \%)$ & $34(9.4 \%)$ & $58(5.8 \%)$ & \\
\hline Open transthoracic & $28(4.3 \%)$ & $49(13.6 \%)$ & $77(7.6 \%)$ & \\
\hline Open transhiatal & $80(12.4 \%)$ & $17(4.7 \%)$ & $97(9.6 \%)$ & \\
\hline Open other & $5(0.8 \%)$ & $2(0.6 \%)$ & $7(0.7 \%)$ & \\
\hline Anastomotic site & & & & 0.50 \\
\hline Cervical & $251(38.9 \%)$ & $153(42.4 \%)$ & $404(40.1 \%)$ & \\
\hline Intrathoracic & $361(55.9 \%)$ & $201(55.7 \%)$ & $562(55.8 \%)$ & \\
\hline None/other/missing & $34(5.3 \%)$ & $7(1.9 \%)$ & $41(4.1 \%)$ & \\
\hline Hospital complication rate & & & & $<0.01$ \\
\hline$<$ national median & $385(59.6 \%)$ & $147(40.7 \%)$ & $532(52.8 \%)$ & \\
\hline$>$ national median & $261(40.4 \%)$ & $214(59.3 \%)$ & $475(47.2 \%)$ & \\
\hline
\end{tabular}

${ }^{\mathrm{a}}$ In kilograms

${ }^{b}$ American Society of Anesthesiologists Score

${ }^{\mathrm{c}}$ Charlson Comorbidity Index

${ }^{\mathrm{d}}$ In conformity with the 7 th edition of the TNM rules for classification

${ }^{\mathrm{e}}$ Minimally invasive

This study has some limitations. It is not required to register in the DUCA when patients are ready for discharge; only the actual date of discharge is entered. Therefore, the underlying reasons for the identified hospital variation remain unclear. The DUCA only registers short-term surgical outcomes (during primary admission or, in case of discharge, in the first 30 post-operative days), therefore the impact of length of hospital stay on delayed complications could not be investigated. In addition, hospital readmissions are registered up to 30 days after primary discharge, 
Table 2 Univariable and multivariable logistic regression analyses to assess the association of patient, tumor, and hospital characteristics with length of hospital stay after uncomplicated esophagectomy in 2015-2018

\begin{tabular}{|c|c|c|c|c|c|c|c|}
\hline \multirow[t]{2}{*}{ Factor } & \multirow[t]{2}{*}{$N$} & \multirow[t]{2}{*}{ OR } & \multicolumn{2}{|c|}{ Univariable analyses } & \multirow[t]{2}{*}{$\mathrm{aOR}$} & \multicolumn{2}{|c|}{ Multivariable analysi } \\
\hline & & & CI $(95 \%)$ & $P$-value & & CI $(95 \%)$ & $P$-value \\
\hline \multicolumn{8}{|l|}{ Sex } \\
\hline Male & 800 & 1 & & & 1 & & \\
\hline Female & 205 & 1.34 & $0.98-1.84$ & 0.06 & 1.37 & $0.95-1.97$ & 0.09 \\
\hline \multicolumn{8}{|l|}{ Age in years } \\
\hline$<65$ & 444 & 1 & & & & & \\
\hline $65-75$ & 477 & 1.08 & $0.83-1.42$ & 0.57 & & & \\
\hline$>75$ & 86 & 1.31 & $0.81-2.09$ & 0.27 & & & \\
\hline \multicolumn{8}{|l|}{ Preoperative weight loss ${ }^{\mathrm{a}}$} \\
\hline None & 334 & 1 & & & & & \\
\hline $1-5$ & 288 & 0.82 & $0.59-1.14$ & 0.23 & & & \\
\hline $6-10$ & 228 & 0.85 & $0.60-1.21$ & 0.38 & & & \\
\hline$>10$ & 121 & 0.92 & $0.59-1.41$ & 0.70 & & & \\
\hline \multicolumn{8}{|l|}{ Body mass index (BMI) } \\
\hline$<20$ & 65 & 1 & & & & & \\
\hline $20-25$ & 493 & 0.66 & $0.39-1.13$ & 0.13 & & & \\
\hline $26-30$ & 328 & 0.76 & $0.45-1.32$ & 0.33 & & & \\
\hline$>30$ & 121 & 0.87 & $0.47-1.61$ & 0.65 & & & \\
\hline \multicolumn{8}{|l|}{ ASA score ${ }^{b}$} \\
\hline I & 199 & 1 & & & & & \\
\hline II & 628 & 1.12 & $0.80-1.57$ & 0.53 & & & \\
\hline $\mathrm{III}+$ & 179 & 1.18 & $0.77-1.80$ & 0.45 & & & \\
\hline \multicolumn{8}{|l|}{$\mathrm{CCI}^{\mathrm{c}}$} \\
\hline 0 & 545 & 1 & & & 1 & & \\
\hline 1 & 235 & 1.33 & $0.97-1.82$ & 0.08 & 1.31 & $0.92-1.86$ & 0.13 \\
\hline $2+$ & 227 & 1.19 & $0.86-1.65$ & 0.28 & 1.13 & $0.78-1.63$ & 0.52 \\
\hline \multicolumn{8}{|c|}{ Previous esophageal or gastric surgery } \\
\hline No & 983 & 1 & & & 1 & & \\
\hline Yes & 21 & 2.43 & $1.02-6.01$ & 0.05 & 1.96 & $0.76-5.17$ & 0.17 \\
\hline \multicolumn{8}{|l|}{ Tumor location } \\
\hline Intrathoracic esophagus & 779 & 1 & & & 1 & & \\
\hline Gastro-esophageal junction & 228 & 0.62 & $0.44-0.85$ & $<0.01$ & 0.81 & $0.54-1.20$ & 0.29 \\
\hline \multicolumn{8}{|l|}{ Histology } \\
\hline Adenocarcinoma & 807 & 1 & & & 1 & & \\
\hline $\mathrm{SCC}$ & 161 & 1.37 & $0.97-1.93$ & 0.07 & 0.90 & $0.60-1.34$ & 0.60 \\
\hline Other & 19 & 0.86 & $0.30-2.21$ & 0.77 & 0.48 & $0.15-1.37$ & 0.19 \\
\hline \multicolumn{8}{|l|}{ Clinical tumor stage $^{\mathrm{d}}$} \\
\hline T0-2 & 244 & 1 & & & & & \\
\hline T3-4 & 727 & 0.81 & $0.61-1.10$ & 0.18 & & & \\
\hline \multicolumn{8}{|l|}{ Clinical node stage $\mathrm{e}^{\mathrm{d}}$} \\
\hline No & 395 & 1 & & & & & \\
\hline $\mathrm{N}+$ & 583 & 1.06 & $0.82-1.39$ & 0.65 & & & \\
\hline \multicolumn{8}{|l|}{ Neoadjuvant therapy } \\
\hline Chemoradiotherapy & 868 & 1 & & & 1 & & \\
\hline None & 64 & 3.34 & $1.99-5.75$ & $<0.01$ & 5.11 & $2.80-9.68$ & $<0.01$ \\
\hline Chemotherapy & 75 & 0.59 & $0.33-1.00$ & 0.06 & 0.90 & $0.45-1.73$ & 0.75 \\
\hline \multicolumn{8}{|l|}{ Salvage surgery } \\
\hline No & 965 & 1 & & & & & \\
\hline Yes & 13 & 1.11 & $0.33-3.36$ & 0.85 & & & \\
\hline
\end{tabular}


Table 2 (continued)

\begin{tabular}{|c|c|c|c|c|c|c|c|}
\hline \multirow[t]{2}{*}{ Factor } & \multirow[t]{2}{*}{$N$} & \multirow[t]{2}{*}{ OR } & \multicolumn{2}{|c|}{ Univariable analyses } & \multirow[t]{2}{*}{$\mathrm{aOR}$} & \multicolumn{2}{|c|}{ Multivariable analysis } \\
\hline & & & CI $(95 \%)$ & $P$-value & & CI $(95 \%)$ & $P$-value \\
\hline \multicolumn{8}{|c|}{ Hospital volume (esophageal resections per year) } \\
\hline$<40$ & 276 & 1 & & & 1 & & \\
\hline$\geq 40$ & 731 & 0.48 & $0.36-0.63$ & $<0.01$ & 0.51 & $0.37-0.70$ & $<0.01$ \\
\hline \multicolumn{8}{|l|}{ Surgical procedure } \\
\hline $\mathrm{MI}^{\mathrm{e}}$ transthoracic & 682 & 1 & & & & & \\
\hline MI transhiatal & 59 & 0.90 & $0.50-1.56$ & 0.71 & 0.51 & $0.27-0.95$ & 0.04 \\
\hline MI other & 27 & 0.33 & $0.10-0.87$ & 0.04 & 0.25 & $0.05-0.85$ & 0.04 \\
\hline Hybrid & 58 & 2.68 & $1.56-4.67$ & $<0.01$ & 2.34 & $1.33-4.16$ & $<0.01$ \\
\hline Open transthoracic & 77 & 3.31 & $2.04-5.46$ & $<0.01$ & 3.56 & $2.09-6.15$ & $<0.01$ \\
\hline Open transhiatal & 97 & 0.40 & $0.23-0.68$ & 0.01 & 0.34 & $0.17-0.61$ & $<0.01$ \\
\hline Open other & 7 & 0.76 & $0.11-3.54$ & 0.74 & 0.76 & $0.09-4.51$ & 0.77 \\
\hline \multicolumn{8}{|l|}{ Anastomotic site } \\
\hline Cervical & 404 & 1 & & & & & \\
\hline Intrathoracic & 562 & 0.91 & $0.70-1.19$ & 0.50 & & & \\
\hline \multicolumn{8}{|c|}{ Hospital complication rate } \\
\hline$<$ National median & 532 & 1 & & & & & \\
\hline$>$ National median & 475 & 2.15 & $1.65-2.74$ & $<0.01$ & 2.18 & $1.62-2.94$ & $<0.01$ \\
\hline \multicolumn{8}{|l|}{${ }^{\text {a In kilograms }}$} \\
\hline \multicolumn{8}{|c|}{${ }^{\mathrm{b}}$ American Society of Anesthesiologists Score } \\
\hline \multicolumn{8}{|c|}{${ }^{\mathrm{c}}$ Charlson Comorbidity Index } \\
\hline \multicolumn{8}{|c|}{${ }^{\mathrm{d}}$ In conformity with the 7 th edition of the TNM rules for classification } \\
\hline
\end{tabular}

the effect of length of hospital stay on longer-term readmission could not be analyzed. The sample of readmitted patients was small, correction for possible confounders using multivariable logistic regression was not possible and uncorrected results were presented.

In conclusion, based on these nationwide audit data, length of hospital stay after an uncomplicated esophagectomy varied significantly between hospitals and ranged from 6.5 to 12.5 days among Dutch hospitals. This variation indicates nationwide improvement could be achieved. This might lead to a substantial reduction of hospital costs. A short hospital stay was not associated with readmission rates. However, readmission rates were higher in patients who were discharged in the weekend. 
Table 3 Patient, tumor, and treatment characteristics of patients with and without 30-day readmission after uncomplicated esophagectomy in 2015-2018

\begin{tabular}{|c|c|c|c|c|}
\hline & $\begin{array}{l}\text { No readmission } \\
N(\%)\end{array}$ & $\begin{array}{l}\text { Readmission } \\
N(\%)\end{array}$ & $\begin{array}{l}\text { Total } \\
N(\%)\end{array}$ & $\begin{array}{l}P \text {-value } \\
\left(\chi^{2} / \text { Fisher }\right)\end{array}$ \\
\hline Total & 933 & 62 & 995 & \\
\hline Sex & & & & 0.41 \\
\hline Male & $744(79.7 \%)$ & $46(74.2 \%)$ & $790(79.4 \%)$ & \\
\hline Female & $188(20.2 \%)$ & $15(24.2 \%)$ & $203(20.4 \%)$ & \\
\hline Missing & $1(0.1 \%)$ & $1(1.6 \%)$ & $2(0.2 \%)$ & \\
\hline Age in years & & & & 0.55 \\
\hline$<65$ & $412(44.2 \%)$ & $28(45.2 \%)$ & $440(44.2 \%)$ & \\
\hline $65-75$ & $439(47.1 \%)$ & $31(50.0 \%)$ & $470(47.2 \%)$ & \\
\hline$>75$ & $82(8.8 \%)$ & $3(4.8 \%)$ & $85(8.5 \%)$ & \\
\hline Preoperative weight loss ${ }^{\mathrm{a}}$ & & & & 0.80 \\
\hline None & $313(33.5 \%)$ & $17(27.4 \%)$ & $330(33.2 \%)$ & \\
\hline $1-5$ & $268(28.7 \%)$ & $18(29.0 \%)$ & $286(28.7 \%)$ & \\
\hline $6-10$ & $213(22.8 \%)$ & $14(22.6 \%)$ & $227(22.8 \%)$ & \\
\hline$>10$ & $109(11.7 \%)$ & $9(14.5 \%)$ & $118(11.9 \%)$ & \\
\hline Missing & $30(3.2 \%)$ & $4(6.5 \%)$ & $34(3.4 \%)$ & \\
\hline Body mass index & & & & 0.87 \\
\hline$<20$ & $61(6.5 \%)$ & $3(4.8 \%)$ & $64(6.4 \%)$ & \\
\hline $20-25$ & $459(49.2 \%)$ & $31(50.0 \%)$ & $490(49.2)$ & \\
\hline $26-30$ & $305(32.7 \%)$ & $19(30.6 \%)$ & $324(32.6 \%)$ & \\
\hline$>30$ & $108(11.6 \%)$ & $9(14.5 \%)$ & $117(11.8 \%)$ & \\
\hline ASA score ${ }^{b}$ & & & & 0.76 \\
\hline I & $185(19.8 \%)$ & $11(17.7 \%)$ & $196(19.7 \%)$ & \\
\hline II & $584(62.6 \%)$ & $38(61.3 \%)$ & $622(62.5 \%)$ & \\
\hline $\mathrm{III}+$ & $163(17.5 \%)$ & $13(21.0 \%)$ & $176(17.7 \%)$ & \\
\hline Missing & $1(0.1 \%)$ & $0(0 \%)$ & $1(0.1 \%)$ & \\
\hline $\mathrm{CCI}^{\mathrm{c}}$ & & & & $<0.01$ \\
\hline 0 & $512(54.9 \%)$ & $26(41.9 \%)$ & $538(54.1 \%)$ & \\
\hline 1 & $223(23.9 \%)$ & $12(19.4 \%)$ & $235(23.6 \%)$ & \\
\hline $2+$ & $198(21.2 \%)$ & $24(38.7 \%)$ & $222(22.3)$ & \\
\hline $\begin{array}{l}\text { Pre previous esophageal or gastric surgery vious esopha- } \\
\text { geal or gastric surgery }\end{array}$ & & & & 1.00 \\
\hline No & $910(97.5 \%)$ & $61(98.4 \%)$ & $971(97.6 \%)$ & \\
\hline Yes & $20(2.1 \%)$ & $1(1.6 \%)$ & $21(2.1 \%)$ & \\
\hline Missing & $3(0.3 \%)$ & $0(0 \%)$ & $3(0.3 \%)$ & \\
\hline Tumor location & & & & 0.21 \\
\hline Intrathoracic esophagus & $726(77.8 \%)$ & $44(71.0 \%)$ & $770(77.4 \%)$ & \\
\hline Gastro-esophageal junction & $207(22.2 \%)$ & $18(29.0 \%)$ & $225(22.6 \%)$ & \\
\hline Histology & & & & 0.19 \\
\hline Adenocarcinoma & $743(79.6 \%)$ & $55(88.7 \%)$ & $798(80.2 \%)$ & \\
\hline Squamous cell carcinoma & $154(16.5 \%)$ & $5(8.1 \%)$ & $159(16.0 \%)$ & \\
\hline Other & $18(1.9 \%)$ & $1(1.6 \%)$ & $19(1.9 \%)$ & \\
\hline Unknown/missing & $18(1.9 \%)$ & $1(1.6 \%)$ & $19(1.9 \%)$ & \\
\hline Clinical tumor stage ${ }^{\mathrm{d}}$ & & & & 0.29 \\
\hline T0-2 & $224(24.0 \%)$ & $18(29.0 \%)$ & $242(24.3 \%)$ & \\
\hline T3-4 & $678(72.7 \%)$ & $40(64.5 \%)$ & $718(72.2 \%)$ & \\
\hline Unknown/missing & $31(3.3 \%)$ & $4(6.5 \%)$ & $35(3.5 \%)$ & \\
\hline Clinical node stage $^{\mathrm{d}}$ & & & & 0.93 \\
\hline
\end{tabular}


Table 3 (continued)

\begin{tabular}{|c|c|c|c|c|}
\hline & \multirow{2}{*}{$\begin{array}{l}\text { No readmission } \\
N(\%)\end{array}$} & \multirow{2}{*}{$\begin{array}{l}\text { Readmission } \\
N(\%)\end{array}$} & \multirow{2}{*}{$\begin{array}{l}\text { Total } \\
N(\%)\end{array}$} & \multirow{2}{*}{$\begin{array}{l}P \text {-value } \\
\left(\chi^{2} / \text { Fisher }\right)\end{array}$} \\
\hline & & & & \\
\hline No & $366(39.2 \%)$ & $25(40.3 \%)$ & $391(39.3 \%)$ & \\
\hline $\mathrm{N}+$ & $539(57.8 \%)$ & $36(58.1 \%)$ & $575(57.8 \%)$ & \\
\hline $\mathrm{Nx}$ & $28(3.0 \%)$ & $1(1.6 \%)$ & $29(2.9 \%)$ & \\
\hline Neoadjuvant therapy & & & & $<0.01$ \\
\hline Chemoradiotherapy & $815(87.4 \%)$ & $42(67.7 \%)$ & $857(86.1 \%)$ & \\
\hline None & $54(5.8 \%)$ & $10(16.1 \%)$ & $64(6.4 \%)$ & \\
\hline Chemotherapy & $64(6.9 \%)$ & $10(16.1 \%)$ & $74(7.4 \%)$ & \\
\hline Salvage surgery & & & & 0.20 \\
\hline No & $894(95.8 \%)$ & $59(95.2 \%)$ & $953(95.8 \%)$ & \\
\hline Yes & $11(1.2 \%)$ & $2(3.2 \%)$ & $13(1.3 \%)$ & \\
\hline Missing & $28(3.0 \%)$ & $1(1.6 \%)$ & $29(2.9 \%)$ & \\
\hline Hospital volume (esophageal resections per year) & & & & 0.74 \\
\hline$<40$ & $253(27.1 \%)$ & $18(29.0 \%)$ & $271(27.2 \%)$ & \\
\hline$\geq 40$ & $680(72.9 \%)$ & $44(71.0 \%)$ & $724(72.8 \%)$ & \\
\hline Surgical procedure & & & & 0.05 \\
\hline $\mathrm{MI}^{\mathrm{e}}$ transthoracic & $635(68.1 \%)$ & $41(66.1 \%)$ & $676(67.9 \%)$ & \\
\hline MI transhiatal & $58(6.2 \%)$ & $1(1.6 \%)$ & $59(5.9 \%)$ & \\
\hline MI other & $22(2.4 \%)$ & $3(4.8 \%)$ & $25(2.5 \%)$ & \\
\hline Hybrid & $52(5.6 \%)$ & $4(6.5 \%)$ & $56(5.6 \%)$ & \\
\hline Open transthoracic & $75(8.0 \%)$ & $2(3.2 \%)$ & $77(7.7 \%)$ & \\
\hline Open transhiatal & $86(9.2 \%)$ & $9(14.5 \%)$ & $95(9.5 \%)$ & \\
\hline Open other & $5(0.5 \%)$ & $2(3.2 \%)$ & $7(0.7 \%)$ & \\
\hline Anastomotic site & & & & 0.55 \\
\hline Cervical & $375(40.2 \%)$ & $26(41.9 \%)$ & $401(40.3 \%)$ & \\
\hline Intrathoracic & $526(56.4 \%)$ & $31(50.0 \%)$ & $557(56.0 \%)$ & \\
\hline None/other/missing & $32(3.4 \%)$ & $5(8.1 \%)$ & $37(3.7 \%)$ & \\
\hline Weekend discharge & & & & 0.05 \\
\hline No & $818(87.7 \%)$ & $49(79.0 \%)$ & $867(87.1 \%)$ & \\
\hline Yes & $115(12.3 \%)$ & $13(21.0 \%)$ & $128(12.9 \%)$ & \\
\hline Length of hospital stay & & & & 0.19 \\
\hline Short admission ( $\leq 9$ days) & $604(64.7 \%)$ & $35(56.5 \%)$ & $639(64.2 \%)$ & \\
\hline Long admission ( $>9$ days) & $329(35.3 \%)$ & $27(43.5 \%)$ & $356(35.8 \%)$ & \\
\hline
\end{tabular}

${ }^{\text {a In kilograms }}$

${ }^{\mathrm{b}}$ American Society of Anesthesiologists Score

${ }^{\mathrm{c}}$ Charlson Comorbidity Index

${ }^{\mathrm{d}}$ In conformity with the 7th edition of the TNM rules for classification

${ }^{\mathrm{e}}$ Minimally invasive

Acknowledgements The authors would like to thank all surgeons, registrars, physician assistants and administrative nurses for data registration in the DUCA database, as well as the Dutch Upper Gastrointestinal Cancer Audit group for scientific input.

Funding No funding was received for the current study.

\section{Compliance with ethical standards}

Disclosures Prof. M.I. van Berge Henegouwen is consultant for Mylan, Johnson \& Johnson, and Medtronic, and received unrestricted research grants from Olympus and Stryker. Prof. R. van Hillegersberg is proctoring surgeon for Intuitive Surgical Inc. and trains other surgeons in robot-assisted minimally invasive esophagectomy. Drs. D.M. Voeten, dr. L.R. van der Werf \& dr. J.W. van Sandick have no conflicts of interest or financial ties to disclose. 
Open Access This article is licensed under a Creative Commons Attribution 4.0 International License, which permits use, sharing, adaptation, distribution and reproduction in any medium or format, as long as you give appropriate credit to the original author(s) and the source, provide a link to the Creative Commons licence, and indicate if changes were made. The images or other third party material in this article are included in the article's Creative Commons licence, unless indicated otherwise in a credit line to the material. If material is not included in the article's Creative Commons licence and your intended use is not permitted by statutory regulation or exceeds the permitted use, you will need to obtain permission directly from the copyright holder. To view a copy of this licence, visit http://creativecommons.org/licenses/by/4.0/.

\section{References}

1. van der Werf LR, Busweiler LAD, van Sandick JW, van Berge Henegouwen MI, Wijnhoven BPL (2020) Reporting national outcomes after esophagectomy and gastrectomy according to the esophageal complications consensus group (ECCG). Ann Surg 271(6):1095-1101

2. Rizk NP, Bach PB, Schrag D, Bains MS, Turnbull AD, Karpeh M, Brennan MF, Rusch VW (2004) The impact of complications on outcomes after resection for esophageal and gastroesophageal junction carcinoma. J Am Coll Surg 198(1):42-50

3. Park KU, Rubinfeld I, Hodari A, Hammoud Z (2016) Prolonged length of stay after esophageal resection: identifying drivers of increased length of stay using the NSQIP database. J Am Coll Surg 223(2):286-290

4. Hii MW, Smithers BM, Gotley DC, Thomas JM, Thomson I, Martin I, Barbour AP (2013) Impact of postoperative morbidity on long-term survival after oesophagectomy. Brit J Surg 100(1):95-104

5. Markar SR, Schmidt H, Kunz S, Bodnar A, Hubka M, Low DE (2014) Evolution of standardized clinical pathways: refining multidisciplinary care and process to improve outcomes of the surgical treatment of esophageal cancer. J Gastrointest Surg 18(7):1238-1246

6. LaPar DJ, Stukenborg GJ, Lau CL, Jones DR, Kozower BD (2012) Differences in reported esophageal cancer resection outcomes between national clinical and administrative databases. $\mathrm{J}$ Thorac Cardiovasc Surg 144(5):1152-1159

7. Carrott PW, Markar SR, Kuppusamy MK, Traverso LW, Low DE (2012) Accordion severity grading system: assessment of relationship between costs, length of hospital stay, and survival in patients with complications after esophagectomy for cancer. J Am Coll Surg 215(3):331-336

8. Zehr KJ, Dawson PB, Yang SC, Heitmiller RF (1998) Standardized clinical care pathways for major thoracic cases reduce hospital costs. Ann Thorac Surg 66(3):914-919

9. Goense L, van Dijk WA, Govaert JA, van Rossum PS, Ruurda JP, van Hillegersberg R (2017) Hospital costs of complications after esophagectomy for cancer. EJSO 43(4):696-702

10. Hoogervorst-Schilp J, Langelaan M, Spreeuwenberg P, de Bruijne MC, Wagner C (2015) Excess length of stay and economic consequences of adverse events in Dutch hospital patients. BMC Health Serv Res 15(1):531

11. Low DE, Kuppusamy MK, Alderson D, Cecconello I, Chang AC, Darling G, Davies A, D'Journo XB, Gisbertz SS, Griffin SM, Hardwick R, Hoelscher A, Hofstetter W, Jobe B, Kitagawa Y, Law S, Mariette C, Maynard N, Morse CR, Nafteux P, Pera M, Pramesh CS, Puig S, Reynolds JV, Schroeder W, Smithers
M, Wijnhoven BPL (2019) Benchmarking complications associated with esophagectomy. Ann Surg 269(2):291-298

12. Kassin MT, Owen RM, Perez SD, Leeds I, Cox JC, Schnier K, Sadiraj V, Sweeney JF (2012) Risk factors for 30-day hospital readmission among general surgery patients. J Am Coll Surg 215(3):322-330

13. Chen SY, Molena D, Stem M, Mungo B, Lidor AO (2016) Postdischarge complications after esophagectomy account for high readmission rates. World J Gastroenterol 22(22):5246-5253

14. Sundaram A, Srinivasan A, Baker S, Mittal SK (2015) Readmission and risk factors for readmission following esophagectomy for esophageal cancer. J Gastrointest Surg 19(4):581-586

15. Low DE, Bodnar A (2013) Update on clinical impact, documentation, and management of complications associated with esophagectomy. Thorac Surg Clin 23(4):535-550

16. Busweiler LAD, Wijnhoven BPL, van Berge Henegouwen MI, Henneman D, van Grieken NCT, Wouters MWJM, van Hillegersberg R, van Sandick JW (2016) Early outcomes from the Dutch upper gastrointestinal cancer audit. Brit J Surg 103(13):1855-1863

17. Wouters MW, Jansen-Landheer ML, Van de Velde CJ (2010) The quality of cancer care initiative in the Netherlands. EJSO 36:S3-S13

18. Johansen NJ, Saunders CM (2017) Value-based care in the worldwide battle against cancer. Cureus 9(2):e1039

19. van der Werf LR, Voeten SC, van Loe CMM, Karthaus EG, Wouters MWJM, Prins HA (2019) Data verification of nationwide clinical quality registries. Brit J Surg Open 3(6):857-864

20. Spiegelhalter DJ (2005) Funnel plots for comparing institutional performance. Stat Med 24(8):1185-1202

21. Osborne NH, Ko CY, Upchurch GR Jr, Dimick JB (2011) The impact of adjusting for reliability on hospital quality rankings in vascular surgery. J Vasc Surg 53(1):1-5

22. Dindo D, Demartines N, Clavien PA (2004) Classification of surgical complications: a new proposal with evaluation in a cohort of 6336 patients and results of a survey. Ann Surg 240(2):205-213

23. R Core Team (2019) R: A language and environment for statistical computing. R Foundation for Statistical Computing, Vienna, Austria. https://www.R-project.org/.

24. Luc G, Durand M, Chiche L, Collet D (2015) Major post-operative complications predict long-term survival after esophagectomy in patients with adenocarcinoma of the esophagus. World J Surg 39(1):216-222

25. Schmidt HM, El Lakis MA, Markar SR, Hubka M, Low DE (2016) Accelerated recovery within standardized recovery pathways after esophagectomy: a prospective cohort study assessing the effects of early discharge on outcomes, readmissions, patient satisfaction, and costs. Ann Thorac Surg 102(3):931-939

26. Preston SR, Markar SR, Baker CR, Soon Y, Singh S, Low DE (2013) Impact of a multidisciplinary standardized clinical pathway on perioperative outcomes in patients with oesophageal cancer. Brit J Surg 100(1):105-112

27. Jiang K, Cheng L, Wang JJ, Li JS, Nie J (2009) Fast track clinical pathway implications in esophagogastrectomy. World J Gastroenterol 15(4):496-501

28. Cerfolio RJ, Bryant AS, Bass CS, Alexander JR, Bartolucci AA (2004) Fast tracking after ivor lewis esophagogastrectomy. Chest 126(4):1187-1194

29. Gemmill EH, Humes DJ, Catton JA (2015) Systematic review of enhanced recovery after gastro-oesophageal cancer surgery. Ann R Coll Surg Eng 97(3):173-179

30. Lee L, Li C, Robert N, Latimer E, Carli F, Mulder DS, Fried GM, Ferri LE, Feldman LS (2013) Economic impact of an enhanced recovery pathway for oesophagectomy. Brit J Surg 100(10):1326-1334

31. Halliday LJ, Doran SLF, Sgromo B, Viswanath YKS, Tucker O, Patel B, Jambulingam PS, Dawas K, Mercer S, Baker C, Mughal 
M, Hanna GB, Moorthy K (2019) Variation in esophageal anastomosis technique - the role of collaborative learning. Dis Esophagus. https://doi.org/10.1093/dote/doz072May15

32. Dutch Institute for Clinical Auditing (DICA). Annual report of the Dutch Upper gastrointestinal Cancer Audit 2018. Accessed 20 May 2020 form https://dica.nl/jaarrapportage-2018/duca.

33. Integraal kankercentrum Nederland. Oesofaguscarcinoom. Landelijke richtlijn, versie 3.1, 2015. Accessed 20 May 2020 form www.oncoline.nl/oesofaguscarcinoom.

34. Boshier PR, Anderson O, Hanna GB (2011) Transthoracic versus transhiatal esophagectomy for the treatment of esophagogastric cancer: a meta-analysis. Ann Surg 254(6):894-906

35. van der Werf LR, Dikken JL, van Berge Henegouwen MI, Lemmens VEPP, Nieuwenhuijzen GAP, Wijnhoven BPL (2018) A population-based study on lymph node retrieval in patients with esophageal cancer: results from the dutch upper gastrointestinal cancer audit. Ann Surg Oncol 25(5):1211-1220

36. Giwa F, Salami A, Abioye AI (2018) Hospital esophagectomy volume and postoperative length of stay: a systematic review and meta-analysis. Am J Surg 215(1):155-162

37. Wouters MW, Gooiker GA, van Sandick JW, Tollenaar RAEM (2012) The volume-outcome relation in the surgical treatment of esophageal cancer: a systematic review and meta-analysis. Cancer 118(7):1754-1763

38. Fernandez FG, Khullar O, Force SD, Jiang R, Pickens A, Howard D, Ward K, Gillespie T (2015) Hospital readmission is associated with poor survival after esophagectomy for esophageal cancer. Ann Thorac Surg 99(1):292-297

39. Bhagat R, Bronsert MR, Juarez-Colunga E, Weyant MJ, Mitchell JD, Glebova NO, Henderson WG, Fullerton D, Meguid RA (2018) Postoperative complications drive unplanned readmissions after esophagectomy for cancer. Ann Thorac Surg 105(5):1476-1482
40. Shah SP, Xu T, Hooker CM, Hulbert A, Battafarano RJ, Brock MV, Mungo B, Molena D, Yang SC (2015) Why are patients being readmitted after surgery for esophageal cancer? J Thorac Cardiovasc Surg 149(5):1384-1391

41. Harhay MN, Jia Y, Thiessen-Philbrook H, Besharatian B, Gumber R, Weng FL, Hall IE, Doshi M, Schroppel B, Parikh CR, Reese PP (2018) The association of discharge decisions after deceased donor kidney transplantation with the risk of early readmission: results from the deceased donor study. Clin Transpl. https://doi. org/10.1111/ctr.13215

42. Hoang CM, Alavi K, Flahive JM, Sturrock PR, Maykel JA, Davids JS (2019) Impact of the "weekend effect" for hospital discharges on readmissions after elective colectomy. Dis Colon Rectum 62(4):476-482

43. Albabtain IT, Alsuhaibani RS, Almalki SA, Arishi HA, Alsulaim HA (2018) Outcomes of common general surgery procedures for patients discharged over weekends at a tertiary care hospital in Saudi Arabia. Ann Saudi Med 38(2):105-110

44. Sanaiha Y, Ou R, Ramos G, Juo YY, Shemin RJ, Benharash P (2018) Day of discharge does not impact hospital readmission after major cardiac surgery. Ann Thorac Surg 106(6):1767-1773

45. Cloyd JM, Chen J, Ma Y, Rhoads KF (2015) Association between weekend discharge and hospital readmission rates following major surgery. JAMA Surg 150(9):849-856

Publisher's Note Springer Nature remains neutral with regard to jurisdictional claims in published maps and institutional affiliations. 